\title{
Micro Hydro Power Plants in Andean Bolivian communities: impacts on development and environment
}

\author{
A. Hueso González ${ }^{1}$, A. Boni Aristizábal ${ }^{1}$, R. Monterde Díaz, $\mathrm{PhD}^{1}$ \\ ${ }^{1}$ Group of Studies on Development, Cooperation and Ethics \\ Departament of Projects Engineering \\ ETSII, edificio 5J, despacho 6 \\ Camino de Vera s/n. 46022. Valencia. Spain. \\ Tfn: (00 34) 963877000 (ext. 85681) \\ Fax: (00 34) 963879869 \\ e-mail: anhuegon@doctor.upv.es
}

\begin{abstract}
This paper's main purpose is to use the capability approach for analysing how micro hydro power plant projects in Bolivia contribute to development and equality. As secondary purposes, it aims to analyse environmental effects and sustainability of the projects and to draw an outline between energy and Human Development. To that end, we examine nine projects implemented in indigenous communities of the Bolivian rural area.

We first explain the role played by energy services in Human Development, focusing on their contribution to the achievement of the Millennium Development Goals. Then we describe the context of nine development aid projects implemented in Bolivia and the characteristics of an impact assessment on these projects committed by the Bolivian Social Grants Program. This assessment is re-examined through the lens of the capability approach. Thus, attention shifts to equality issues in the fields of ethnicity, gender and income. Finally we analyse the environmental effects and the sustainability of the proects.
\end{abstract}

This paper is an example of "best practice project", showing how renewable energy can help improving people's life in a clean and sustainable way and how the capability approach is a powerful tool for assessing this improvement.

Keywords

Small hydro energy, sustainability, development aid project, impact assessment

\section{ENERGY AND HUMAN DEVELOPMENT}

\section{A. THE ROLE OF ENERGY SERVICES IN DEVELOPMENT}

Energy can be generated in different ways, but its enduse form is usually movement, electricity or heat. It can be used for lighting, cooking, refrigeration, telecommunication, transport, moving machines or running a computer; these are called energy services.

Improving energy services includes many different aspects, such as generating of electricity, using or producing more adequate fuels, seeking more efficient and hygienic methods for heating and cooking, installing manual water pumps, etc.

Access to energy services is not directly included in the Millennium Development Goals (MDGs), adopted by the world leaders in 2000 in the Millennium Summit (United Nations), as development goals to achieve until 2015. However, it is considered by United Nations Development Programme (2005) to be "a prerequisite to the achievement of all eight MDGs". In fact, it's central to many aspects of poor people's everyday life and plays an important role in development.

On one hand, it's estimated that in many countries a third of household expenditures are for energy services. Furthermore many people, especially women and girls, spend on energy related activities -like cooking or gathering fuelwood and water- more than 6 hours a day, affecting negatively to their welfare (UNDP, 2005).

On the other hand, the potentialities of energy services in terms of education, health, gender issues or productivity attest that energy is a crucial means to Human Development.

The link between energy services and Human Development has been studied by United Nations Development Programme (2005), who has shown the correlation between per capita energy use and Human Development Index in different countries and in different periods. They have also analysed the links between energy and each Millennium Development Goal.

\section{B. MICRO HYDRO POWER AND THE MILLENNIUM DEVELOPMENT GOALS}

We will concentrate on the energy services provided by micro hydro power plants in isolated rural areas; private and communal uses of electricity in a wide range of tension and power. They can contribute to each Millennium Development Goal in different ways: 
Goal 1: Eradicate extreme poverty and hunger

Electricity can be useful for agro processing, small service business and industrial activities -mills, shops or metalwork-, which generate jobs and incomes and diversify income sources. In addition, the expenditures on energy services decrease. Food processing and the use of refrigeration allow an improvement on diet, contributing to eradicate hunger and malnutrition.

Goal 2: Achieve universal primary education

Having home lighting and electricity at school may attract teachers to rural areas and permits use of multimedia tools. Students can study after dusk and spend less time in energy related activities.

Goal 3: Promote gender equality and empower women

Electricity can reduce the time many women and girls spend in household tasks. Therefore, they can have more possibilities to study and become literate. Other jobs traditionally reserved to women like shopkeeper or craftworks may improve with the access to electricity service. Public lighting improves public safety in rural communities, which is very important for women.

\section{Goal 4: Reduce child mortality} and

Goal 5: Improve maternal health

In addition to the better diet and more hygienic cooking conditions, mothers and children can benefit from improved medical service; electricity enables refrigeration, adequate lighting, telecommunication and use of medical technology. These in turn, permit vaccination, sterilization and an improvement in time and quality of the medical service. These working conditions may attract moreeducated doctors and nurses.

Goal 6: Combat HIV/AIDS, malaria and other diseases

The general improvement of medical service and the awareness campaigns on radio and TV can help combating these diseases.

Goal 7: Ensure environmental sustainability

The clean generation of electricity with a micro hydro power plant ensures respect to the environment, as its small size minimizes the impact on the river. Access to electricity provokes a drop of the use of other fuels, which reduces the emission of greenhouse gases, contributing to fight the climate change. Related to the target of safe drinking water, electricity allows to pump water if superficial water isn't safe enough.

Goal 8: Develop a global partnership for development

Electricity improves substantively the access to information and telecommunication. These are crucial inputs for raising awareness and allowing the creation of networks and interest groups.

\section{MICRO HYDRO POWER PLANTS IN RURAL COMMUNITIES IN BOLIVIA}

\section{A. THE PROJECTS}

The projects studied were designed by the Hydrology and Hydraulics Institute of the Universidad Mayor de San Andrés (UMSA) in La Paz (Bolivia) and were implemented in small rural communities isolated from the national electricity grid in La Paz. Funding and monitoring came mostly from the Small Grants Program of the Global Environment Facility (SGP/GEF) embodied in the United Nations Development Programme of Bolivia (UNDP). A smaller part of the projects were funded by the National Program for Climate Change of the Bolivian Vice Ministry for Planning and Environment. There was always cofunding from regional and local public institutions. Most of the projects began with a demand of the community to the Hydrology and Hydraulics Institute for building a plant.

The projects consist of the implementation of a micro or pico run-of-the-river hydro power plants in the community. The power or the plants range from 1 to 70 $\mathrm{kW}$, depending on the size of the community (between 5 to 250 families), the uses planned and the specific conditions of the place where the plant is built. Generally, the plants have some common elements: In the river basin, a small dam is built in order to divert part of the water from the river. The water and flows through a channel or a pipe, arriving to the surge tank. In the tank starts the penstock that delivers the water to the powerhouse, where the water impacts on the turbine, making it roll with the electric generator coupled to it. The turbines used in the projects are usually Pelton turbines, but it depends on the height difference and the flow. Electricity is generated in the three-phase generator, with a phase-phase voltage of $380 \mathrm{~V}$ with 1500 revolutions per minute. Electricity is regulated and stabilized when it goes through the electronic controller, which sends the difference between generation and demand to dissipating resistors. Three lines from the power house to the different parts of the community provide electricity to the household, to comunal spaces and for public lighting. As electricity demand is very low during the day -when the peasants are working in their fields - there is a lot of electricity available during this period of time. Thus, some of the projects include a communal income-generating activities: food processing, carpentry...

Each community creates an Electrification Committee and organizes itself in order to participate in the process and work for building the plant. Local materials are used as much as possible and a considerable proportion of the installed machines are made in Bolivia. An important part of the project is the training for operating and managing the plant. The members of the community who helped building the plant become owners of the plant. They elect a Board of Directors for the Electrification Committee that is responsible for managing the plant: charge the users, administer the reparations' fund, hire a local operator, 
arrange informative meetings and ensure the maintenance and the sustainability.

\section{B. THE COMMUNITIES}

From the 9 communities involved in the study, 8 of them (Calzada, Camata, Ch'allapampa, Charía, Choro, Chucura, Flor de Mayo and Samañapampa) are in the subtropical Bolivian Yungas, the transitional regions between the Altiplano and the lowland, belonging the last one (Agua Blanca) to the Altiplano. The inhabitants of these communities are mainly Quechua and Aymara indigenous people. They mostly come from the Andean Altiplano and immigrated to the Yungas in the past 50 years, seeking higher agricultural productivity in its fertile soils. Many of them cultivate coca, whose leaf is used by Andean cultures for medicinal and ceremonial purposes and consumed for her mild stimulating effect either by chewing or as coca leaf tea. The current high prize of the coca leaf makes family farm quite profitable. These communities didn't have access to electricity before the projects, and used candles, LP Gas, batteries and kerosene for lighting.

\section{THE STUDY}

The Bolivian Social Grants Program committed an impact assessment of the different projects implemented by the Hydrology and Hydraulics Institute. The purpose was to study these projects in order to assess their effects on the community and with regard to climate change. Thus, it had to identify causes and variables that affected to the success of the projects. The results would be useful for improving the design of further projects.

The study consisted mainly of qualitative field trips made by the researcher, who visited the communities for 1 to 4 days in the first months of 2007 . This means that the trips took place two years after the end of the last project and eleven years after the first one's end. The limitations of time, resources and information (no baseline data were available) determined the methodology used. It was an expost study with 9 communities as participant groups and 2 similar communities as comparison groups. The main unit of analysis was the household. In order to be sensitive to intra-familiar distribution and power relations, special attention was put on this issue when possible. The survey shared many characteristics with a case study because it was considered crucial to understand the project's effects in its contexts. Quantitative information was crossed with qualitative perceptions of the members of the community, the latter playing an important role in identifying the impacts the project had contributed to achieve. Some of the data collection methods employed in the field studies were: semi-structured and informal interviews with key stake-holders, interviews with preset questions, records data collection, direct observation, etc.

\section{THE EFFECTS UNDER THE LENS OF THE CAPABILITY APPROACH}

\section{A. THEORETICAL FRAMEWORK}

We want to re-examine the effects generated by the micro hydro power plant projects, going a step further from the MDGs. We will use the capability approach in order to enrich the analysis and try to better understand the role played by the energy services provided in the process of development. The capability approach, developed by Amartya Sen and other authors, understands development as the "process of expanding the real freedoms that people enjoy" (Sen, 1999). Incorporating issues like education, health or the right to participate, this approach provides a more integral view of development, challenging more traditional views focused exclusively on income. Thus, it offers an "alternative approach to evaluation that focuses directly on freedom, seen in the form of individual capabilities to do things that a person has reason to value" (Sen, 1999).

In order to delimit this evaluative space, there are two crucial concepts defined by Amartya Sen:

- The concept of functionings, which "reflects the various things a person may value doing or being" (Sen, 1999)

- A person's capability, that "refers to the alternative combinations of functionings that are feasible for her to achieve" (Sen, 1999), that is, her real freedom to choose the things to do and the ways of being she has reason to value.

In short, we want to analyse how the projects contributed to expand people's capabilities and what functions they achieved.

These expansion and achievements vary from one community to the other, inside one community and in one household. This indicates that energy services can be important means for expanding some capabilities, but there are other means and some external and internal factors that play a role in the conversion of means into achievements.

Robeyns work is very interesting for understanding that issue. Between the means (endowments) that enable the expansion of capabilities, we can find on one side goods and services and on the other social institutions. Energy services could be conceptualized as goods and services that have characteristics that allow functionings. But "the relation between a good and the functionings to achieve certain beings and doings is influenced by three groups of conversion factors" (Robeyns, 2005). Conversion factors are material and non-material, internal and external circumstances that shape people's opportunities, and they can be personal, social or environmental. Furthermore, there are "circumstances that influence the choices that people make from the capability set" (Robeyns, 2005). 
The following figure can help us to visualize and illustrate all the concepts:

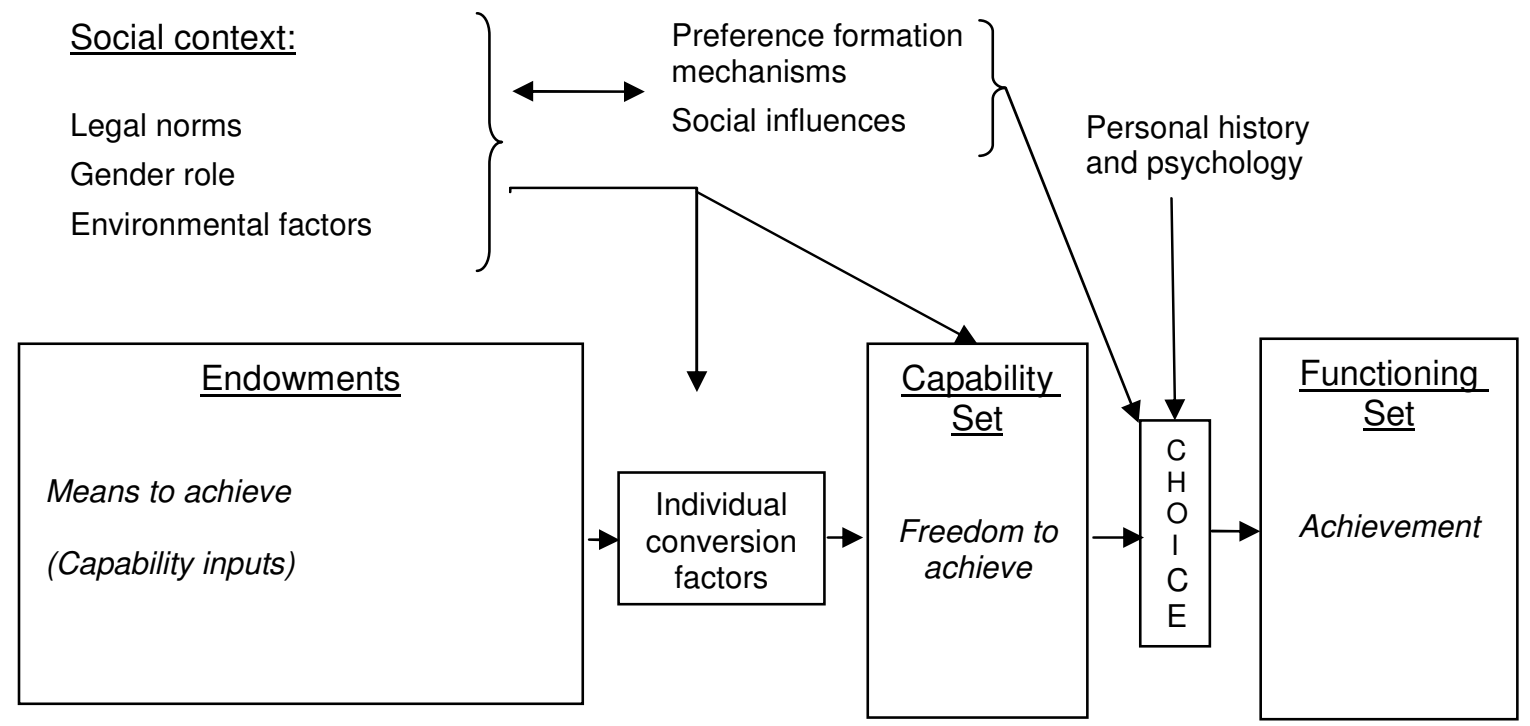

Figure 1: Representation of the capability approach (adapted from Robeyns (2005) and Chiappero (2008))

Some energy services are used to provide goods and services (endowments) and therefore we will first list the effects generated by the project, which enable the endowments used afterwards in the simplified representations with the capability sets they contributed to enhance.

\section{B. DIRECT EFFECTS}

In the economic domain, the following results were identified:

- A 54\% reduction in household expenditures for energy services; candles, kerosene, liquefied petroleum gas (LPG) and batteries versus electricity.

- The money flowing out of the community for energy services has gone down significantly $(75 \%)$

- One part-time job created in each community for the operator of the plant

- Creation and improvement of small businesses

- No need of travelling for buying lighting fuels.

In the educational domain:

- With house lighting, students have better conditions and more time for studying. The percentage of the study time that takes place after dawn is $55 \%$ (60\% for girls and $50 \%$ for boys).

- Lighting in the school is cause of better conditions for students and teachers and the possibility of teaching after dawn. There was teaching of basic literacy for adults in 5 communities.

- In the communities where there was already a school, new educational tools have been purchased: computer rooms, TVs, DVDs, etc.

In the health domain:

- The smoke generated by lighting at home has been eliminated.

- The reduction on the use of lighting fuels has cut down the risk of fires.

- In 3 communities -the ones with a health centrelighting and new equipment have improved the health service.

- Refrigeration is used for enhancing diet and keeping medicines.

- High-quality lighting allowed more hygienic conditions, for example for cooking.

In the communications and social life domain:

- Having electricity has spread the use of radio and television ( $80 \%$ of the homes visited had one).

- One public telephone has been installed in 3 communities.

- Public lighting has permitted more leisure opportunities for children and security for walking at night -which is especially important for women.

- With cheap lighting, people stay awake more time at night -approximately one and a half hour- and this has permitted more social life and leisure time (watch TV, listen to music, etc.)

- The number and quality of meetings and parties has increased.

\section{CAPABILITIES EXPANSION AND ACHIEVED FUNCTIONINGS}

These effects are the endowments for some capability and functionings sets. They are represented in the figures below, which refer to the 5 main functionings in which the project has had substantial influence. Neither the social context nor the circumstances that affect people's choice are included in the figures, but analysed after each figure and partly in the following chapter. 


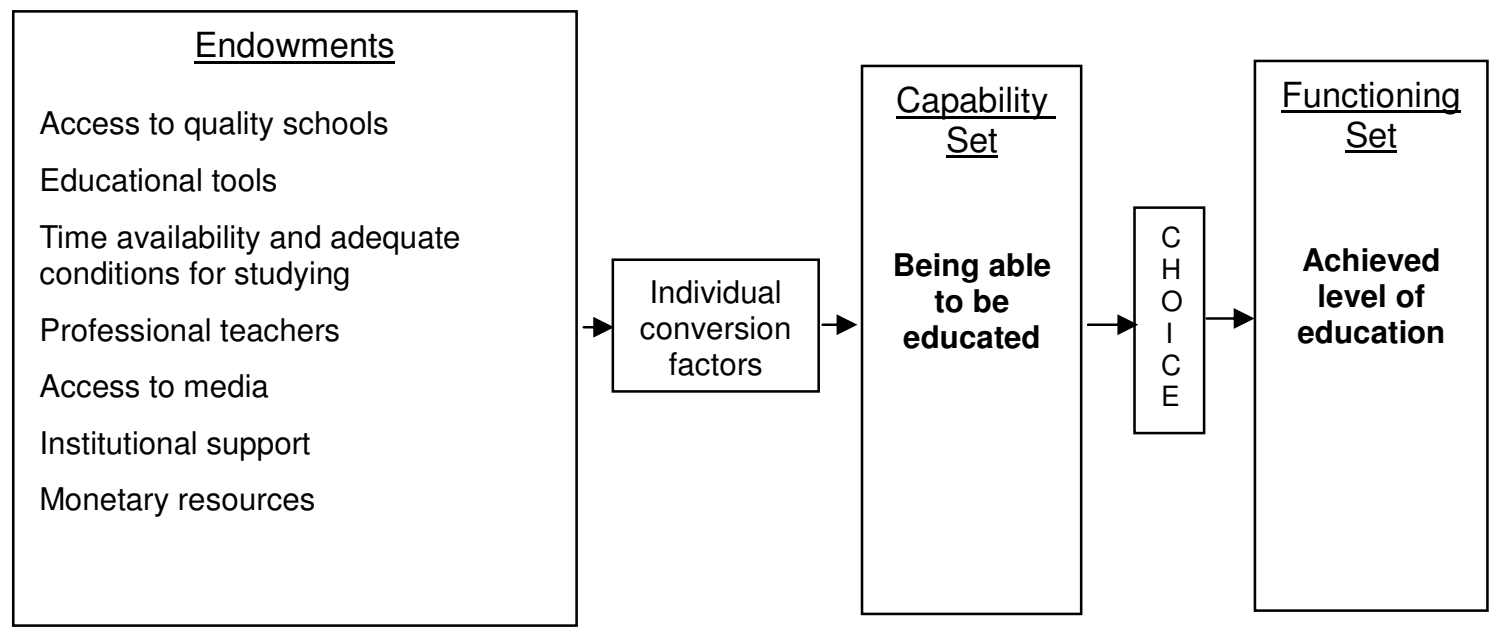

Figure 2: Representation of the capability approach referred to level of education

The endowments -being similar in the different communities- have helped expanding the capability to be educated. By the way, individual conversion factors are important here, because with the same endowments, children have a different capability set than adult people, who might have a social constraint for using this available time and other means for studying. Gender role is also important here, affecting to the conversion factors of women and girls -who should take care of the family's needs- and, psychologically, to the choice women make. This turns out in a narrower capability set, preventing them to be able to achieve functionings men may achieve.

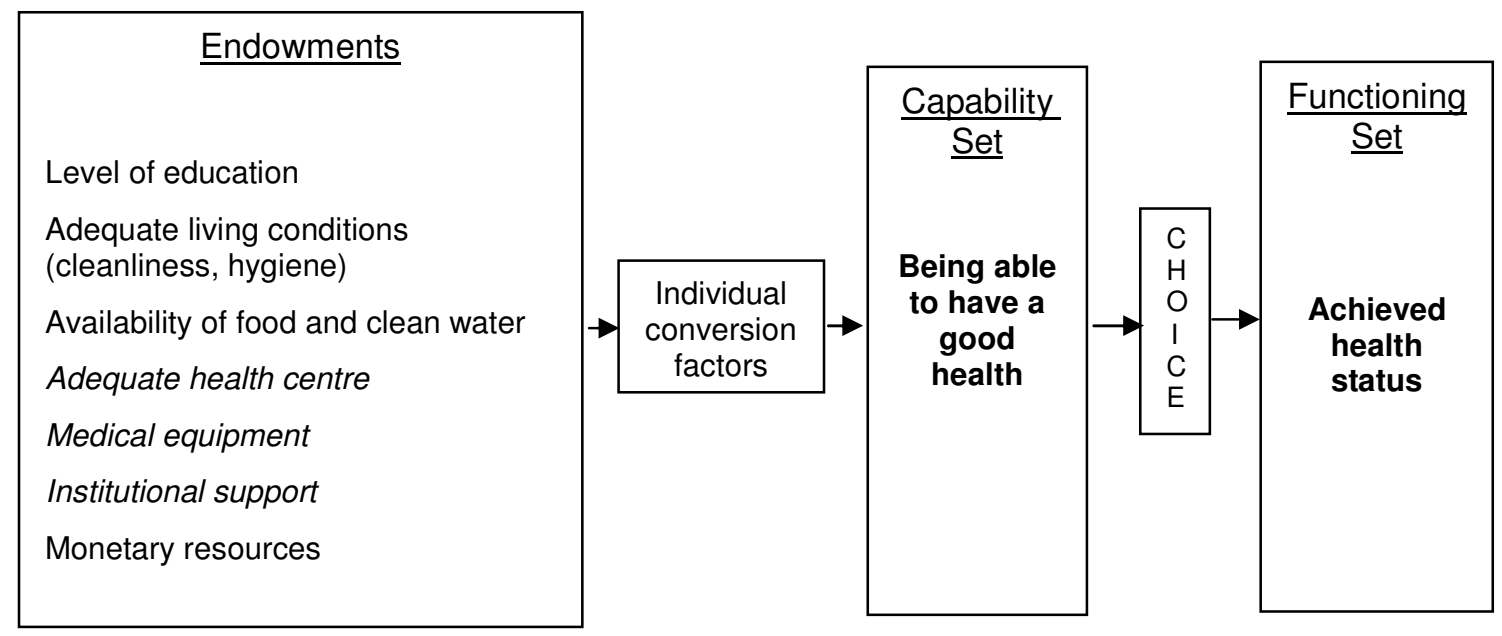

Figure 3: Representation of the capability approach referred to health status

The achieved health status is different for each person, and different from one community to the other. It mainly depends on the endowments shown in italics in Figure 3: in the few communities where there's institutional support, there's a good health centre that takes profit from the potentialities of electricity. In these communities, the capability to have good health is bigger. In any case, $80 \%$ of the people that participated in the study stated that his health status had improved, mainly due to the reduction of indoor smokes. 


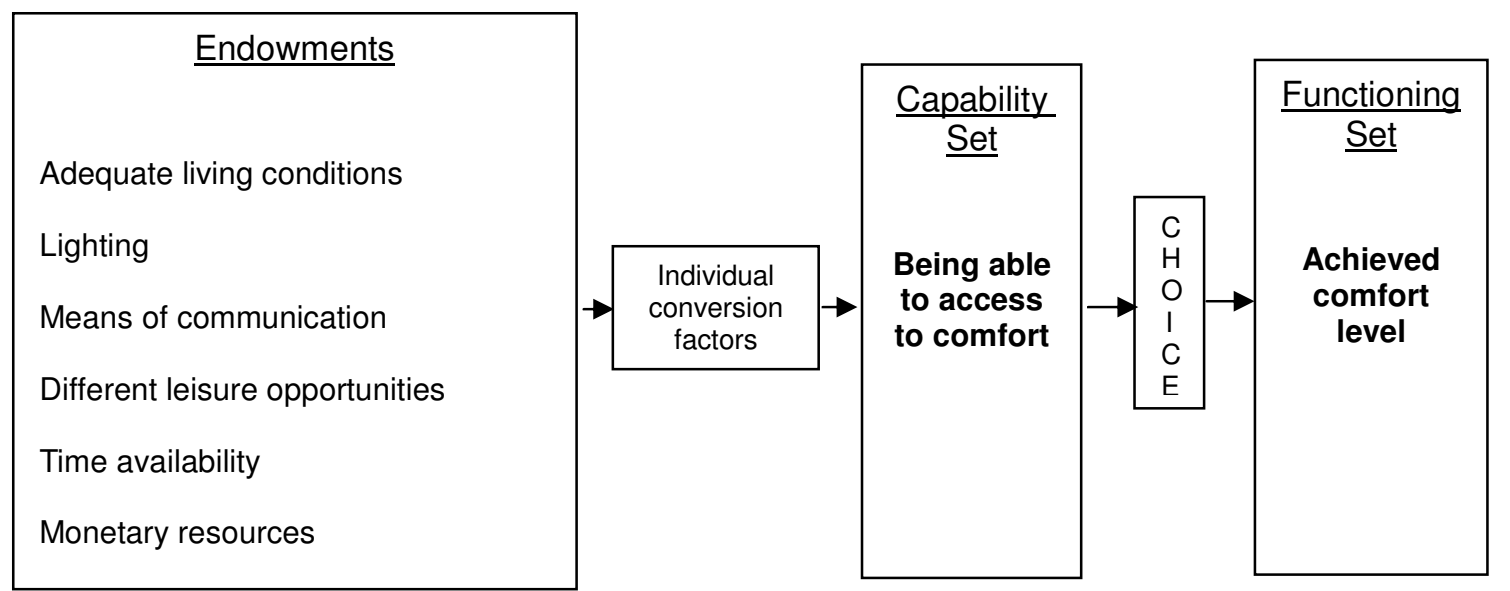

Figure 4: Representation of the capability approach referred to comfort level

The improvement of living conditions has been general in all the communities. $51 \%$ of the sample said his living standard had improved and $40 \%$ said it had improved a lot.
Possibility of watching TV is very valued, because of the increase of access to information and of leisure opportunities. However, there were some negative opinions on that, because TV was seen as cause of less communication at home and worse performance at school.

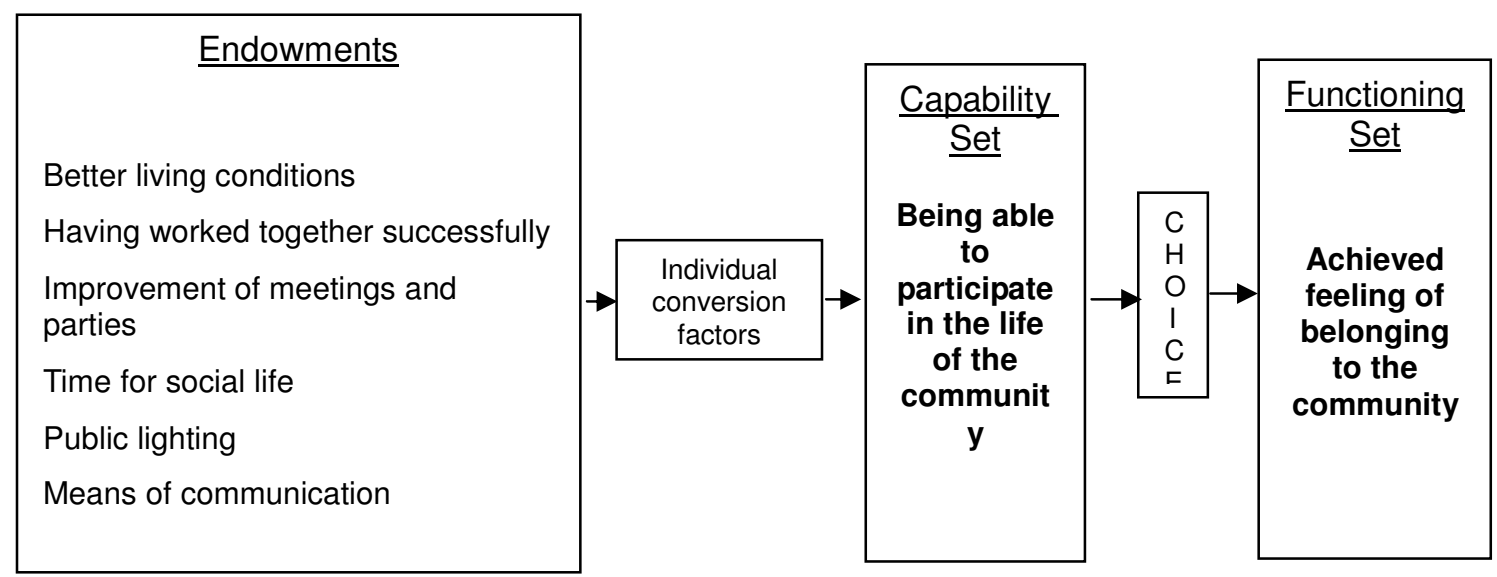

Figure 5: Representation of the capability approach referred to the feeling of belonging to the community

The endowments appear in almost every community and have generated in the people a feeling of being part of something. In addition, the improvements in the living conditions were cause of a decrease in the emigration to $\mathrm{La}$ Paz. This causes and at the same time contributes to the achieved functioning of feeling part of the community.

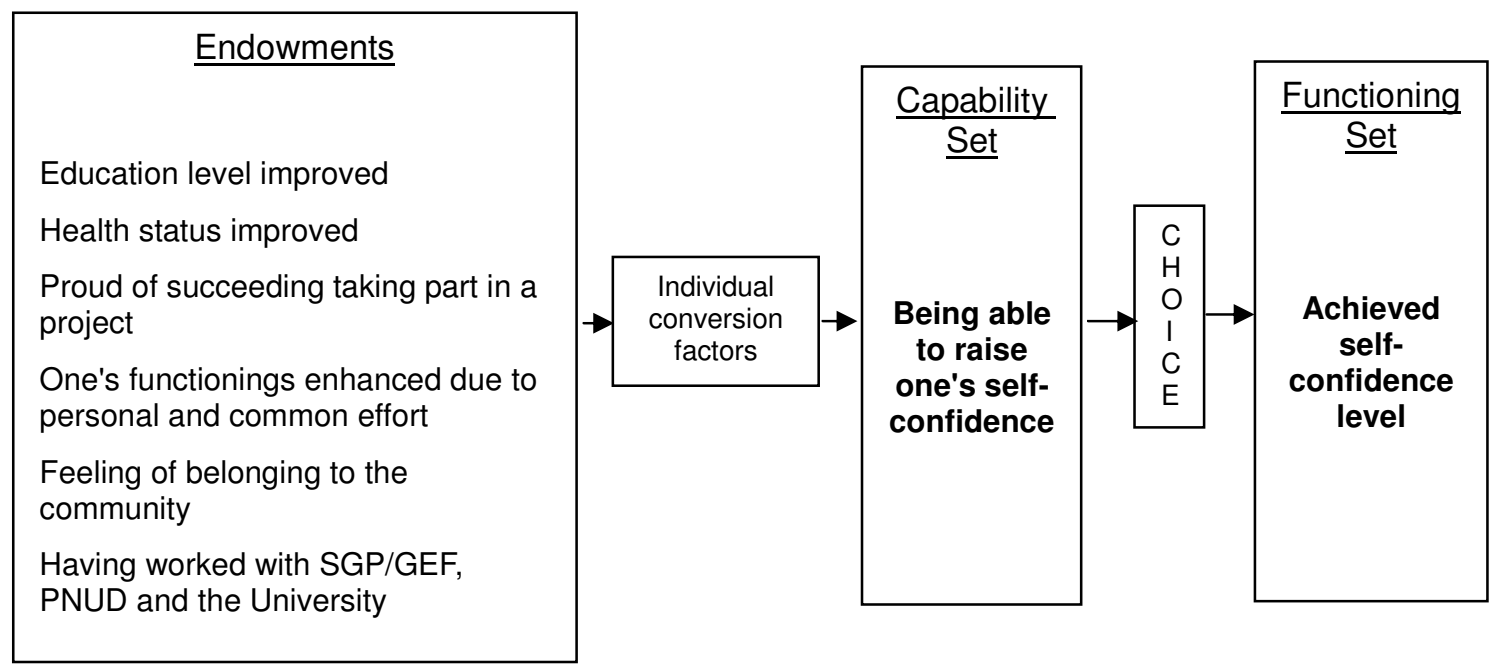

Figure 6: Representation of the capability approach referred to level of self-confidence 
The members of each community decided to start the project, worked hard and succeeded. Now it belongs to them and they have shown themselves to be able to administer and operate the plant and the electrical service. In addition, they enjoy an enhancement of their achieved functionings. All this contributes to their satisfaction and to a rise of self-confidence. The words of one member of the community illustrate this very clearly: "The moral [the project] has given to us is that the one who works in unity, can achieve whatever he sets out, he only needs a goal. The project has made us conscious of this capacity."

The ethnicity is an important conversion factor in this case. Being indigenous was cause of shame in Bolivia for centuries. Since some decades, this perception is slowly changing, and the president of Bolivia being indigenous has helped to spread this change. In the context of the project, this change of perception is a social conversion factor that helps boosting self-confidence.

Another individual conversion factor that should be considered is sex. Women neither participate as much as men in the project's processes nor are equitably represented in the Electrification Committees. Therefore, the possibility of raising one's self-confidence is not so noticeable in women.

\section{EQUALITY}

We've seen that the expansion of capabilities and the achieved functionings are not the same for everybody. On one side, we have the endowments, which are different between the communities, like we have already stated. On the other side, the individual conversion factors, influenced by social context and one's role in it, are cause of more differences between and within communities. Both of them lead us to an important topic we haven't discussed yet: equality.

We will focus on how the projects affect to equality in the fields of ethnicity, gender and income.

Following the National Statistics Institute of Bolivia, the indigenous people represent $50 \%$ of the population of the country (2001), but they are $75 \%$ of the population of the rural area. It is remarkable that the access to electricity reaches $67 \%$ of the population of Bolivia, but only $33 \%$ of the population in the Bolivian rural area (OLADE, 2005). This is a sign of how indigenous people in Bolivia are discriminated, having fewer opportunities to access to electricity and to many other basic services like education or health care. As we have seen, this deprivation of endowments leads them to a narrower capability set than non-indigenous people. The projects are implemented in rural communities where almost everybody is indigenous, being thus an input for ethnic equality. Further, the projects are also contributing to this goal by involving -at least economically- public institutions in the project. This helps attracting the attention of these institutions to the community and its need for support and might be the starting point of a long-term commitment to the members of the community.
The design of the projects didn't pay attention to gender equality. Undoubtedly, there have been some specific improvements in women's living conditions and one could think this is 'good enough' to gain more equality towards men. However, we've already seen that women's and girls' real freedom to choose the kind of life they want to lead arrives to a lesser extent than men's. The culturally accepted gender role exerts negative influence on their capability sets and their achieved functionings. In addition, this inequality is reflected again after the project, neutralizing the specific improvements mentioned above; some women said that instead of having gained more time for them, now they have less time, because with lighting they have to attend to their family until later. This shows that gender inequality cannot be solved just by providing services: there must be a process that permits a social and cultural shift to more equal power and gender relationships.

Another important intra-community inequality refers to the income levels. In many communities there are a few -mainly older- people with very low income that can't afford paying for the electricity provided by the plant. In some communities, the Electrification Committee has set a 'solidarity tariff' for this people, who enjoy lower prices for their electricity. In other communities -especially where there isn't plenty of power- this people don't have access to electricity. On the other side, they can benefit anyway of public lighting and other public uses (for example in the health centre).

\section{ENVIRONMENTAL EFFECTS AND SUSTAINABILITY}

\section{A. EFFECTS ON CLOSE ENVIRONMENT AND CLIMATE CHANGE}

Although some local effects on the environment were considered, the focus was mainly on the impact on climate change -the reduction of emissions of carbon dioxide equivalent.

The local effects of the project on the environment are small, due to the little dimensions of the plant and the use of a renewable energy source. Even the water that is taken from the river comes back to it some hundreds of meters "later", after going through the turbine. A positive effect on the local environment is caused by a reduction of $73 \%$ of the batteries consumed before the project. These batteries normally ended their days buried, burnt or just left anywhere. The chemical substances of the batteries were, either directly or dragged by the rains, polluting the environment, especially the water of the river. A very rough estimation assessed the monthly reduction of water pollution in 14.000 cubic metres.

Regarding global warming, electrical lighting replaced lighting fuels like candles, LP Gas and kerosene. The field study permitted to assess the monthly reduction of the use of these fuels per family. 
Table 1: Fuel consumption reduction

\begin{tabular}{|l|l|}
\hline Reduction of the use of candles (number) & 22,32 \\
\hline
\end{tabular}

Reduction of the use of kerosene (litres) 3,51

\begin{tabular}{|l|r|}
\hline Reduction of the use of LP Gas (garrafas) & 0,36 \\
\hline
\end{tabular}

The national emission factors allowed to calculate that every month, the projects avoid the emissions of 16,6 tons of carbon dioxide equivalent $(22,53 \mathrm{~kg}$ per family).

\section{B. SUSTAINABILITY}

In development projects one key issue is sustainability. Too often, the effects of the projects disappear gradually after the end of the funding. Therefore, it's very important to analyse sustainability in its different dimensions.

Regarding institutional sustainability, the appropriation of the project by the community has to be highlighted. They value very much the change allowed by electricity in their everyday life and are thus very committed with the durability of this living conditions. Further, having contributed with their own work to the construction of the plants makes this appropriation even deeper. This guarantees the institutional commitment of the community, and the adequate administration observed during the research corroborates it.

Economically, the fact that the amount paid for electricity is lower than the ancient expenses in fuels is enough for assuring the sustainability. The reparations' fund -though being a bit weak in the first years- permits the communities to maintain the plant in perfect condition.

The technical sustainability is generally good, although the operators' training should be enhanced. It's an important point that the machines and the design of the plant were made in La Paz, so that the communities can easily ask the Hydrology and Hydraulics Institute for help when they have any problem.

Concerning environmental sustainability, we have already seen that the local and global impacts on the environment are mainly positive, contributing to the sustainability. Moreover, even though it's a issue that doesn't depend on the project, the effects of the climate change and the drought in some of the communities has been cause of too low water level to generate the amount of electricity demanded during the dry season.

\section{CONCLUSIONS}

\section{A. SUMMARISING}

The analysis of the projects' effects through the lens of the capability approach has shown that micro hydro power plants can improve people's capability sets and achieved functionings remarkably. These improvements were more significant in relation to five fields:

- Education level: the improvement of the conditions and means for studying and the availability of time have contributed to the expansion of the capability to be educated, allowing better achievements in education level.

- Health status: substitution of lighting fuels for electricity lighting has reduced indoor smokes and has permitted more hygiene. In addition, health care services have improved. This results in more real opportunities of having good health.

- Comfort level: enhancement of living conditions and access to means of communication and leisure opportunities result in an expansion of the capability of accessing to comfort.

- Feeling of belonging to the community: various public energy services have enhanced the possibility of participating in social life and, as a consequence, there has been a deeper feeling of belonging to the community.

- Self-confidence: the processes and the joint work in the projects and their success have been crucial inputs to the achievement of higher self-confidence levels.

Furthermore, the capability approach has helped to draw attention on the equality as well, since the capability set and the achieved functionings differ from one person to the other, depending on the social context and the individual conversion factors. We have seen that being a woman -with its implicit gender role- can be a handicap for enjoying all the gained possibilities. The projects, not dealing with gender issues, aren't capable to contribute to the cultural and social shift needed for reaching more equal gender relationships. Further, the project contributes to equality between indigenous and non-indigenous people in Bolivia, the latter enjoying higher access to electricity and other services.

The use of small renewable energy plants like these micro hydro power plants have mainly positive effects in both the close and the global environment. The most remarkable aspect is the reduction of the emissions of 16,6 tons of carbon dioxide equivalent every month. The sustainability of the projects is guaranteed in all its dimensions: economically, institutionally, technically and environmentally.

\section{B. LESSONS}

This paper is an interesting example of the potentialities of the capability approach as evaluative space for energy-based projects. The approach permits a deeper understanding of the processes involved in the project and its contexts and of how they lead to certain effects. Furthermore it allows putting the focus on people's freedom to lead the life they value and thus obtain a richer assessment on their development process.

These projects are an example of 'best practice projects' in the field of renewable energies. The micro hydro power plant projects have contributed to enhance the living conditions and expand the capabilities of the Andean Bolivian communities in a clean and sustainable way. This should draw our attention to the fact that technology is a powerful tool for Sustainable Human Development, when adapted to local context and appropriated by the people who are going to profit from it. 


\section{REFERENCES}

Alkire, Sabina. 2002. Valuing Freedoms. Sen's Capability Approach and Poverty Reduction, Oxford University Press.

Chiappero, Enrica. 2008. Operationalization of the capability approach: from theory to practice, 2008. Lecture in the 'Master en Políticas y Procesos de Desarrollo', Universitat Politècnica de València.

Modi, V., S. McDade, D. Lallement, and J. Saghir. 2006. Energy and the Millennium Development Goals, Energy Sector Management Assistance Programme, United Nations Development Programme, UN Millennium Project and World Bank.

OLADE. 2005. Diagnóstico del sector energético en el área rural de Bolivia. Viceministerio de Electricidad y Energías Alternativas.

Robeyns, Ingrid. 2005. The capability approach: a theoretical survey. Journal of Human Development, March 2005.

Sen, Amartya. 1999. Development as Freedom, Oxford University Press.
Sen, Amartya. 1990. Development as capability expansion, MacMillan.

UNDP, 2005. Energizing the Millennium Development Goals. A Guide to Energy's Role in Reducing Poverty, United Nations Development Programme.

UN-Energy. 2005. The Energy Challenge for Achieving the Millennium Development Goals, United Nations System.

UN, 2001. Road map towards the implementation of the United Nations Millennium Declaration, Report of the SecretaryGeneral, General Assembly - United Nations.

Velo Garcia, Enric et. al.. 2006. Energía, participación y sostenibilidad, Associació Catalana d'Enginyeria Sense Fronteres.

\section{Note:}

You can access on-line to the study (only in Spanish) that is the base of the analysis of this paper: "Estudio sobre el impacto social, económico y ambiental de pequeñas centrales hidroeléctricas implantadas en comunidades rurales de $\mathrm{La} \mathrm{Paz}$, Bolivia"

Full study:

http://personales.alumno.upv.es/anhuegon/pmch.pdf Summary:

http://personales.alumno.upv.es/anhuegon/resumenpmch.pdf 